\title{
Demanding expectations: exploring the experience of distributed heat generation in Europe
}

Louise Reid and Katherine Ellsworth-Krebs

\begin{tabular}{|c|c|}
\hline Date of deposit & 01122020 \\
\hline Document version & Author's accepted manuscript \\
\hline Access rights & $\begin{array}{l}\text { (c) } 2020 \text { Elsevier Ltd. All rights reserved. This work has been } \\
\text { made available online in accordance with publisher policies or } \\
\text { with permission. Permission for further reuse of this content } \\
\text { should be sought from the publisher or the rights holder. This is } \\
\text { the author created accepted manuscript following peer review and } \\
\text { may differ slightly from the final published version. }\end{array}$ \\
\hline $\begin{array}{l}\text { Citation for } \\
\text { published version }\end{array}$ & $\begin{array}{l}\text { Reid, L \& Ellsworth-Krebs, K 2021, 'Demanding expectations: } \\
\text { exploring the experience of distributed heat generation in } \\
\text { Europe', Energy Research and Social Science, vol. 71, } 101821\end{array}$ \\
\hline $\begin{array}{l}\text { Link to published } \\
\text { version }\end{array}$ & https://doi.org/10.1016/j.erss.2020.101821 \\
\hline
\end{tabular}

Full metadata for this item is available in St Andrews Research

Repository at: https://research-repository.st-andrews.ac.uk/

\begin{tabular}{l|l|l|} 
University of & FOUNDED \\
St Andrews & 1413
\end{tabular}




\section{Demanding expectations: exploring the experience of distributed heat generation in Europe}

Keywords: microgeneration; energy demand; domestic practices; home; online journal; UK; Netherlands.

Highlights:

- Installation and initial experience are key aspects influencing everyday domestic practices

- Householders anticipated and planned greater capacity and/or demand for heating in the future

- First time an online journal has been developed for householders with microgeneration heating in the UK and Netherlands

\section{Introduction}

Decarbonising energy production is a key global goal (Sustainable Development Goal 7) and increasing renewable energy generation is essential to address the climate emergency, energy security and affordability. The majority of policy and scholarship on renewable energy focuses on electricity generation despite heating accounting for roughly a third of carbon emissions world-wide [1]. This is partly because of the complexity of intervening and altering countries' heating systems as heat is produced by millions of separate installations at different scales (e.g. district heating to household heat pumps) from different fuels (e.g. biomass, coal, electricity) and across a range of temperatures. Due to these factors, heat metering is uncommon making it harder to develop renewable heating policies or measure their effectiveness. Housing is a particularly important sector, accounting for a quarter of national energy consumption [2] with heating representing the main demand of energy for space (c.53\%) and water (c.16\%) [3]. While (biomass and solar) district heating schemes and innovations in hydrogen are important interventions to increase renewable heat at neighbourhood and city-scales, the focus on microgeneration for heat ${ }^{1}$ (hereafter $\mathrm{MfH}$ ) in the home is also essential considering the decentralised nature of heat generation.

When compared to microgeneration for electricity, uptake rates of $\mathrm{MfH}$ technologies are low [4-6]. While explanations for adoption decisions and uptake of microgeneration technologies are a dominant area of enquiry $[7,8]$, the majority of this work follows from techno-econometric traditions resulting in a focus on the building fabric, technical specifications and individual psychology of householders, and lacks more sophisticated understandings of how and why households install and live with renewable energy technologies. In contrast, this paper responds to calls to give 'voice to

\footnotetext{
${ }^{1}$ Microgeneration for heat $(\mathrm{MfH})$ is a label we use to describe small-scale systems of heat provision (up to 50 kilowatts, which is the maximum capacity for government subsidies), normally used by households, smallbusinesses or community buildings. In this paper we are only concerned with household MfH.
} 
consumers on this topic, which has been mostly silent in previous research' [9, p.15]. Drawing on practice informed energy studies $[10,11]$ and Science and Technology Studies (STS) scholarship on futures $[12,13]$ we argue that it is crucial to understand not only how MfH systems are adopted, used, and adapted, but how this is informed by views of the future. Therefore, in this paper we present a cross-cultural comparison of $32 \mathrm{UK}$ and Dutch households living with the $\mathrm{MfH}$ technologies of ground or air ground source heat pump systems (GSHP/ASHP), biomass boilers or solar thermal heating.

The paper begins by providing an overview of scholarship on microgeneration, focusing on major lines of enquiry related to understanding uptake and satisfaction, before adopting energy futures scholarship to enhance these debates and raise questions of energy sufficiency and changing expectations affecting demand. The third section explains the methodology which includes location of research, sample, design and reflections. The fourth and fifth sections explore our results and how these $\mathrm{MfH}$ technologies were embedded into everyday lives and visions of the home. The final section offers concluding remarks, emphasising that a focus on the motivations or barriers of installation is too limited in terms of explaining satisfaction with $\mathrm{MfH}$ technologies.

\section{Literature Review}

Scholarship around microgeneration can largely be separated into two dominant areas: explanations for adoption decisions and the performance of microgeneration systems. Indeed, it has been recognised that most empirical research concerning microgeneration focuses on the adoption decision [8], and that overall, the empirical explanations for such activity are based on work with microgeneration for electricity $[14,15]$ not heat $[1,5,16]$. Moreover, not only is the adoption decision and its wider sociotechnical temporal context often overlooked (i.e. adoption is treated as a discrete entity, independent from a household history, or prior experience with similar systems etc.), how it ties into householders' imagined futures has almost entirely been ignored. In part, this is because of the dominance of techno-econometric traditions and the resulting focus on the building fabric, technical specifications and individual psychology of householders. In this literature review, we explore key debates on adoption decisions before moving on to set out an alternative approach drawing on literature surrounding energy practices and socio-technological expectations.

\subsection{Adoption of Micro- and distributed generation Technologies}

Research on uptake rates for micro- and distributed generation has been approached from theoretical and empirical perspectives across a wide range of disciplines $[14,15,17,18]$. Theoretical work has largely been informed by theories of innovation and technology diffusion [19,20], transition [21], or theories of consumer behaviour [17,22]. Empirical work has employed a wide range of methodological approaches from economic valuation $[3,23]$ to, more infrequently, case studies of subjective 
explanations $[16,24]$. The former, which dominate the literature, adopt a neoclassical framework assuming private households are utility-maximising consumers which is used 'for explaining switching behaviour...and explanatory variables [such as] socio-economics and socio-demographic characteristics' [18, p.97]. Whilst research on installation rates for MfH uptake is limited relative to that for electricity generation, where it does exist, it also tends to focus on sociodemographic, economic, and housing characteristics $[23,25,26]$. Despite this, research on domestic renewable energy is now demonstrating that 'building owners' decisions are rarely driven by sophisticated financial analyses of alternatives [7]' [27, p.580], casting doubt on approaches which place the utilitymaximising consumer at the core of household decision-making.

The type of technology and its performance accounts for a significant area of academic enquiry on microgeneration. Three main catalysts for installation have been identified [22]: a problem situation (e.g. existing heating system breaking down and requiring replacement), an opportunity situation (e.g. an incentive is created which encourages installation), or as a part of a new construction. Allan and McIntyre [25] demonstrate that local social effects help explain adoption in the context of visible installations (e.g. solar PV). Nonetheless, we suggest that there are 'energy cultures' ${ }^{2}$ [28] at play which may influence installation in all of these cases. In other words, variation in uptake rates result from local and or social contexts, suggesting that 'more qualitative and case-study research is merited to understand the significance of local level factors in early and later diffusion stages' [27, p.588]. Nascent literature on adoption decisions recognises the utility of approaches which seek to understand the experience of the $\mathrm{MfH}$ householder or installer $[16,26,29-21]$ and how that varies by place and time [32,22]. Yet we still lack appropriate understandings of how ideas of the future, specifically what householders aspire and expect of their homes, may impact on current desires and energy demand.

\subsection{Everyday expectations of home and future aspirations affecting microgeneration uptake and use}

Although scholarship on living with $\mathrm{MfH}$ systems $[8,34,35,36]$ is growing, the ontological and methodological basis upon which this scholarship has developed retains a largely natural science/technical perspective $[24,30]$. In response, a focus on the everyday has arisen which attends to understanding how domestic practices co-evolve with changing patterns of energy demand $[10,11$, 37]. Furthermore, research on comfort in energy studies demonstrate that new technologies and building fabrics impact expectations of home as well as what energy is used for [26, 38-40]. These

\footnotetext{
${ }^{2}$ Energy cultures is a specific area of academic enquiry which explores how 'energy behaviours are embedded within the physical and social contexts of everyday life, and how they are both repetitive and heterogeneous' (28, p.117).
} 
socio-material changes thus can run counter to policy goals and reducing demand. Kuijer and Watson [41] offer an illustration of this analysing new practices in UK homes emerging between 1920 and 1970. During this period, the introduction of central heating systems led to more of the home being heated as the family spread out from socialising around an open fire in the living room to individually studying and playing in heated bedrooms. This example points to the way in which altering heating systems can impact on more than perceptions of thermal comfort to also shift family interactions, expectations of privacy and use of space in the home. Ellsworth-Krebs et al. [38] found that installing microgeneration technologies did not happen in isolation, these were carried out at the same time as other home improvements such as adding a guest bedroom to make family visits easier or en-suites to provide more individual privacy. Home comfort, home-making and future housing aspirations [38, 42] influence installation decisions and resulting energy patterns.

Emotional [43] and normative expectations of home [44], including how that influences energy demand and retrofitting [38, 45-47] have been acknowledged elsewhere. Hansen (23, p.140), for instance, has alluded: 'understandings of what constitutes a nice home can play a huge role in the ways households refit their homes'. Without consideration of excess and how to 'live sufficiently well' [48] more energy demanding 'needs' may be negotiated and normalised [49]. This is interesting as the focus on the future, and planning $\mathrm{MfH}$ around visions of a future home requires, we argue, a more 'relational, time sensitive' understanding of energy demand (50, p.130). Bringing an imagined future into frame draws attention to the temporality of heating practices, not just the day-to-day routines and rhythms of everyday life but the stability and future of these over time [51,52]. Development of microgeneration technologies need to be understood within this wider context of how visions and expectations of the future inform their installation and use.

Within a broader field of work on environmental futures $[53,54]$ and socio-technical futures $[13,55]$ energy futures scholarship has investigated energy systems [12] governance regimes $[56,57]$ scenarioplanning and forecasting [58]. This scholarship has highlighted how 'ideal' visions of future energy users and the attributes of future energy systems are 'literally and materially scripted into' these energy systems [12, p.2]. Science and Technology Studies (STS) dominates future studies: exploring different ways of thinking about the future, specifically the anticipatory concepts of expectations, visions and imaginaries [59]. These distinct concepts have been used to 'explore how the future, as a dimension of the present, is constructed through practices as well as through discourse and thus contributes to the production and reproduction of social reality' $[59, p .473]$. This means that conceptualisations of the future are co-constructed with the present in material ways. For example, the default settings on a household central heating system are imbued with judgements about what time of day, duration and temperature the home needs to be heated. These judgements are based on 
the anticipation of daily routines and rhythms, such as who will be in the home, how often, for how long, and what they will be doing. In effect, current heating settings in some way make possible (or not) future daily practices (e.g. the availability of heat may make staying at home, or being less active at home, possible).

The future has therefore been recognised as an often 'taken-for-granted category' [60, p.778], one deserving of interrogation given that 'the experience of the presence of certain futures is used to demand, justify and legitimate certain forms of action to secure life (including inaction)' [60, p.787]. Coming from Human Geography (HG), research explores the differing logics of anticipation, using precaution, pre-emption and preparedness as concepts to understand a variety of futures [60]. Together, the HG and STS scholarship emphasise the importance of anticipatory practices, which are also fundamental, we argue, in the way that $\mathrm{MfH}$ systems are designed, chosen, installed, and used based on an understanding of future home life, practices and energy requirements, whether explicit or implicit. These anticipatory practices are held by all those involved in the development, selling, installing, and use of such systems - but importantly, by the householder who chooses to adopt a heating technology or chooses a home with these systems. For instance, a prediction of what (maximum and minimum) energy demand will be required. Many of these assumptions and anticipations are held within the imaginations of those who design, develop and install the MfH systems [see 29 on installer perspectives], but we need to also consider anticipated use by 'nonexperts' or by householders whose own imaginations and anticipatory practices will evolve over time, impacting on the use of and demand for $\mathrm{MfH}$ systems. Yet non-expert anticipatory practices are seldom explored or visible in the literature [61], particularly in relation to energy [see 62 for an account of users in smart grid design], and especially $\mathrm{MfH}$. In this study, we therefore advance thinking around $\mathrm{MfH}$, moving debates on from issues of adoption and performance to bring richer and more sophisticated understandings of how and why households install and live with microgeneration technologies, particularly in relation to future imaginaries of homes and associated energy demands.

\section{Methodology}

In this paper we present qualitative self-reported data collected through an online photo journal to provide insights on the subjective experience of $\mathrm{MfH}$ technology. In this section we explain site selection (3.1), our research method (3.2), and describe our sample (3.3), reflecting on the overall methodological process (3.4). Our ontological approach was inductive and exploratory in nature following well-established qualitative research values [63], rather than seeking to 'test' for causality. Indeed, in a review of methods in energy social science, online qualitative methods such as photo- 
journals do not feature as commonly utilised [63], so its use in this way was exploratory, which we also reflect on in 3.4. To our knowledge this is the first time this methodological approach has been used in a study on renewable heating and represents something of a departure from traditional inperson qualitative research. The attraction of this approach was that it would allow us to undertake cross-country comparative research within a single week, simultaneously collecting data from 32 households, asynchronously. This has the added advantage in the context of heating practices to ensure that variables such as external ambient temperature were common, and because it would allow participants to upload and discuss photographs. It also reduced travel to undertake fieldwork.

\subsection{Location of research}

Both the UK and the Netherlands have historically been amongst the European countries with the lowest proportion of registered renewables and microgeneration systems [64], and a focus on them offers both the opportunity to understand why this is, and the greatest potential for improvement. For example, in 2016, renewable energy accounted for $19.1 \%$ of total energy use for heating and cooling in the EU-28, but only 7\% in the UK and 5.5\% in the Netherlands [64]. For the same period, household renewable energy consumption accounted for $15.9 \%$ (EU-28), 4.4\% (UK), and $4.8 \%$ (NL) of final energy consumption [64] $]^{3}$. To encourage the adoption of $\mathrm{MfH}$, both countries have adopted a similar policy approach using subsidies; in the UK this has been the Renewable Heat Initiative (RHI) (2014-2020, f117million in 2018/19) [65] and in the Netherlands the Investeringssubidie Duurzame Energie (ISDE) [66] (2016-2020, €100million budget for 2018) [67]. For both, the type of technology installed determines the amount of subsidy received and households only qualify for the subsidy if an approved installer has done the work and a valid Energy Performance Certificate has been provided. An important distinction between the two schemes is that prior to applying for the ISDE, the MfH technology must already be installed and paid for, unlike the RHI where a householder can apply for upfront funding to help fund the purchase and installation of the technology (called the 'Assignment of Rights') [68].

\subsection{Research design}

Digital methods are an approach gaining popularity in the social sciences [69-71], because of participant convenience, the number of participants who may be involved, and the level of information they divulge. Yet despite online and virtual methods [72, 73], digital methods [71] and netnography [74] being popular neologisms, they are seldom used in domestic energy or microgeneration research. We have used them in our work for this paper because we believe online

\footnotetext{
${ }^{3}$ Figures from 2016 are included because this was the year data collection occurred. The most up-to-date figures are for 2018: renewable energy accounted for $21.1 \%$ of total energy use for heating and cooling in the EU-28, but only $7.5 \%$ in the UK and $6.1 \%$ in the Netherlands [65].
} 
discussions are an extension of casual conversations and may accurately reveal householders' areas of interest and concern [75]. In this paper, we predominantly rely on the qualitative data generated through the platform which took the form of written entries from participants. This is because it provides insights on the subjective experience about the technology. Indeed, 'the use of qualitative methods in energy research enables the examination of personal narratives associated with everyday use of energy and energy-related practices [28]' [9, p.12]. Throughout we asked participants to upload photographs or videos to help contextualise their written entries, to add greater richness and context to the written accounts, although few did this (see 3.4).

The online journal was hosted by an organisation running online qualitative research projects. The platform required no special software for either the researchers or participants, with only a standard web browser and internet connection necessary to allow access by smartphone or computer. The data were self-reported and collected using an online journal over the course of 7 days in the winter of 2016. There were 7 days of the online journal, with a separate section visible to participants each day. Given the intense and compacted period of data collection, we were particularly keen to avoid participant fatigue [76] so alternated sections which asked for more or less information. The 7 section topics covered: 1) 'you and your home' which sought information about the participant, the age, location, type, fabric and environmental performance of the home; 2) 'your household life' which asked about daily, weekly and seasonal routines (within the past 12 months) which may impact on energy demand, as well as the sociodemographic makeup of the household; 3) 'renewable energy' which asked about the date, installer, capacity of their installation, motivations for installation, skills they gained, and maintenance practices; 4) 'energy demand' which asked about consumption and the impact of having renewable energy on demand, as well as whether or not government payments were received/would make a difference to installation; 6) 'improving support', where participants were asked what advice they would have liked to receive and would give to others, as well as how they thought more people could be encouraged to uptake renewables; 7) 'your future home' which asked about the extent to which smart devices were used, how they anticipated future demand, the extent to which they had planned for the end-of-life of their installation, and their dream home. The choice of these topics was informed by the literature, particularly social practice theory [40], and we developed the guidance/prompts/questions so that we would capture the competencies (skills), materials, and meanings (routines) which make up practices.

Throughout the week, prompting of the participants was undertaken by the authors, and during the 7 days we prompted 328 times. This process provided greater insight as the researchers were able to respond to comments and ask for clarification (e.g. you said 'quooker'; I've never heard of that before. Can you tell me what it is please?), further explanation (e.g. why did you think this happened), or for 
evidence to support the contribution (e.g. can you please upload a photo to show us and help us understand). Indeed, this was a resource-intensive task for the researchers not least as much input was required outside of conventional working hours but was only for a very short period of 7 days. The researchers shared fieldnotes (e.g. who had been responded to, which comments required followup), which were also useful in reflecting on the value of the method.

The data were explored using thematic analysis (initially using the elements of social practice theory e.g. meanings, materials, competencies [40]) involving a process of data immersion and interpretation by both authors [77]. Following Sovacool et al., [63], the approach was exploratory to understand the reasons for accounts from participants, investigating both individual narratives and shared perspectives between (e.g. according to installation and whether UK/NL) and across the whole sample. We also attempted to assess the role of the methodology during our analysis. Transcripts of the online discussions, in addition to uploaded media, were downloaded from the platform and coded into categories. Ethical approval was awarded by the University of St Andrews, and pseudonyms are used.

\subsection{Sample}

A total of 32 households were involved in the study, 16 from the UK and 16 from the Netherlands. A purposive sampling strategy [77] was used to recruite householders with one of three $\mathrm{MfH}$ systems (see table 1), in common with many studies where the aim was to understand experiences of households in their adoption of a specific technology $[8,18]$. Three key criteria guided the strategy 1 ) that households had one of three types of MfH system (e.g. GSHP/ASHP; Biomass; Solar Thermal); 2) these households were evenly split between UK and NL; and, 3) that at least $50 \%$ of the households should have more than 2 occupants. The aim of criteria 3 was to avoid a sample skewed with older affluent households who had installed the technology for financial return, a bias we observed in our previous work [16], but also to reflect the diverse demands of heat in households with multiple occupants. Table 1 explains nature of household, unless otherwise stated, children were aged under 18. All adult household members could participate, but in all cases, it was just a single representative who did. The sampling strategy was developed by the authors of this study, and a recruitment agency was used to ensure diversity in terms of installation type and geographical location.

Of the 32 households, $78 \%$ were owner-occupiers, $65 \%$ of the homes were detached or semidetached, and $84 \%$ installed the $\mathrm{MfH}$ systems themselves. The houses ranged in age: $65 \%$ were pre2002 , and $31 \%$ post $-2002^{4}$. The householders had higher average income than the national population in both the UK and Netherlands [our participants average annual (net) income; UK: $£ 40,000-60,000$

\footnotetext{
${ }^{4}$ Note that 2002 was chosen because it was the date of a UK Building Regulation which made changes to regulations around conservation of energy, a post-2002 house denotes greater energy efficiency
} 
NL: $€ 40,000-60,000$ compared with 2016 OECD data [78] UK $£ 23,292$ and NL $€ 26,851$ ], which is perhaps a reflection of who has the means to engage with renewable energy installations, ownership of devices to access the internet, data allowances to allow participation, and/or online literacy.

Table 1: Sample characteristics [Note: GHSP = Ground Source Heat Pump; ASHP = Air Source Heat Pump; DK = don't know; and, for Capacity, some participants chose to record this in terms of kW, others in terms of spend]

\begin{tabular}{|c|c|c|c|c|c|c|c|}
\hline Pseud & Country & Age & Household & $\begin{array}{c}\mathrm{HH} \\
\text { Income }\end{array}$ & Tech & $\mathrm{EPC}^{5}$ & Capacity \\
\hline Gemma & UK & 61 & $\begin{array}{l}\text { Living with } \\
\text { partner }\end{array}$ & $<£ 20,000$ & GSHP & DK & $2.5 \mathrm{~kW}$ \\
\hline Maud & $\mathrm{NL}$ & 34 & $\begin{array}{l}\text { Married } \\
\text { with } 1 \text { child }\end{array}$ & $\begin{array}{l}€ 20,000- \\
40,000\end{array}$ & ASHP & $\mathrm{C}$ & $11 \mathrm{~kW}$ \\
\hline Andrew & $\mathrm{NL}$ & 34 & Single & $\begin{array}{l}€ 20,000- \\
40,000\end{array}$ & GSHP & DK & DK \\
\hline Mila & $\mathrm{NL}$ & 38 & $\begin{array}{ll}\text { Married } & \\
\text { with } & 3 \\
\text { children } & \end{array}$ & $\begin{array}{l}€ 40,000- \\
60,000\end{array}$ & ASHP & A & $6.3 \mathrm{~kW}$ \\
\hline Fenna & $\mathrm{NL}$ & 37 & $\begin{array}{l}\text { Married } \\
\text { with } 1 \text { child }\end{array}$ & $\begin{array}{l}€ 60,000- \\
80,000\end{array}$ & GSHP & $B$ & $10 \mathrm{~kW}$ \\
\hline Rosa & $\mathrm{NL}$ & 44 & $\begin{array}{l}\text { Married } \\
\text { with } \\
\text { children }\end{array}$ & $\begin{array}{l}€ 60,000- \\
80,000\end{array}$ & GSHP & A & DK \\
\hline Julia & $\mathrm{NL}$ & 58 & Single & $>€ 80,000$ & GSHP & $B$ & $1000 \mathrm{kWh}$ \\
\hline Jack & UK & 39 & $\begin{array}{l}\text { Married } \\
\text { with } \\
\text { children }\end{array}$ & $\begin{array}{l}£ 20,000- \\
£ 40,000\end{array}$ & GSHP & C & DK \\
\hline Pamela & UK & 24 & $\begin{array}{l}\text { Living with } \\
\text { partner, } 2 \\
\text { children }\end{array}$ & $\begin{array}{l}£ 20,000- \\
£ 40,000\end{array}$ & GSHP & $B$ & DK \\
\hline Thomas & UK & 58 & Single & $\begin{array}{l}£ 0,000- \\
40,000\end{array}$ & GSHP & $B$ & 700kWh/month \\
\hline Tanya & UK & 46 & $\begin{array}{ll}\text { Married } & \\
\text { with } & 3 \\
\text { children } & \\
\end{array}$ & $\begin{array}{l}f 60,000- \\
f 80,000\end{array}$ & GSHP & $B$ & $12 \mathrm{~kW}$ \\
\hline Jennifer & UK & 38 & $\begin{array}{l}\text { Married } \\
\text { with } \\
\text { children }\end{array}$ & $\begin{array}{l}£ 40,000- \\
£ 60,000\end{array}$ & GSHP & DK & $100 \mathrm{Kw}$ per m2 \\
\hline Denise & $\mathrm{NL}$ & 41 & Married & & Biomass & $\mathrm{C}$ & DK \\
\hline Ruben & $\mathrm{NL}$ & 43 & $\begin{array}{ll}\text { Married } & \\
\text { with } & 2 \\
\text { children } & \end{array}$ & $<€ 20,000$ & Biomass & DK & DK \\
\hline Hannah & $\mathrm{NL}$ & 51 & $\begin{array}{l}\text { Married } \\
\text { with } 1 \text { child }\end{array}$ & $\begin{array}{l}€ 20,000- \\
40,000\end{array}$ & Biomass & D & $8 \mathrm{~kW}$ \\
\hline
\end{tabular}

\footnotetext{
${ }^{5}$ The EPC should change if an installation takes place, but we included it here for information, and because we reflect on significance of householders who said they 'didn't know' what their EPC was (see section 4).
} 


\begin{tabular}{|c|c|c|c|c|c|c|c|}
\hline Faas & $\mathrm{NL}$ & 53 & $\begin{array}{ll}\text { Married } & \\
\text { with } & 4 \\
\text { children } & \end{array}$ & $>€ 80,000$ & Biomass & DK & $35 \mathrm{~kW}$ \\
\hline Milou & $\mathrm{NL}$ & 40 & $\begin{array}{l}\text { Married } \\
\text { with } 1 \text { child }\end{array}$ & $>€ 80,000$ & Biomass & $B$ & $9 \mathrm{~kW}$ \\
\hline Ben & $\mathrm{NL}$ & 41 & $\begin{array}{l}\text { Married } \\
\text { with } 1 \text { child }\end{array}$ & $>€ 80,000$ & Biomass & DK & $25 \mathrm{~kW}$ \\
\hline June & UK & 62 & $\begin{array}{l}\text { Married } \\
\text { with } \\
\text { children }\end{array}$ & $\begin{array}{l}£ 20,000- \\
£ 40,000\end{array}$ & Biomass & $E$ & $26 \mathrm{~kW}$ \\
\hline Bram & UK & 34 & $\begin{array}{l}\text { Living with } \\
\text { partner \& } 3 \\
\text { children }\end{array}$ & $\begin{array}{l}f 40,000- \\
£ 60,000\end{array}$ & Biomass & $A$ & $5 \mathrm{MW}$ \\
\hline Laura & UK & 33 & $\begin{array}{l}\text { Living with } \\
\text { partner }\end{array}$ & $>£ 80,000$ & Biomass & DK & $50 \mathrm{~kW}$ \\
\hline Rebecca & UK & 36 & $\begin{array}{l}\text { Married } \\
\text { with } 2 \\
\text { children }\end{array}$ & $>£ 80,000$ & Biomass & $\mathrm{E}$ & $20 \mathrm{~kW}$ \\
\hline Jack & UK & 57 & $\begin{array}{l}\text { Married } \\
\text { with } \\
\text { children }\end{array}$ & $>£ 80,000$ & Biomass & $E$ & $4000 \mathrm{~kW}$ \\
\hline Dameer & UK & 58 & $\begin{array}{l}\text { Married } \\
\text { with } 1 \text { adult } \\
\text { child }\end{array}$ & $>£ 80,000$ & Biomass & $\mathrm{D}$ & DK \\
\hline Sander & $\mathrm{NL}$ & 58 & $\begin{array}{l}\text { Living with } \\
\text { partner }\end{array}$ & $\begin{array}{l}€ 20,000- \\
40,000\end{array}$ & $\begin{array}{l}\text { Solar } \\
\text { Thermal }\end{array}$ & $\mathrm{D}$ & $\begin{array}{l}700 \text { euro in first } \\
\text { year }\end{array}$ \\
\hline Heidi & $\mathrm{NL}$ & 52 & $\begin{array}{l}\text { Married } \\
\text { with } 2 \\
\text { children }\end{array}$ & $\begin{array}{l}€ 20,000- \\
40,000\end{array}$ & $\begin{array}{l}\text { Solar } \\
\text { Thermal }\end{array}$ & A & DK \\
\hline Rupert & $\mathrm{NL}$ & 50 & Married & $>€ 80,000$ & $\begin{array}{l}\text { Solar } \\
\text { Thermal }\end{array}$ & B & $\begin{array}{l}\text { solar } 1600 \mathrm{kWh} / \\
\text { annum } \\
\text { wood stove } 7 \mathrm{~kW}\end{array}$ \\
\hline Peter & UK & 35 & $\begin{array}{l}\text { Married } \\
\text { with } 1 \text { child }\end{array}$ & $>£ 80,000$ & $\begin{array}{l}\text { Solar } \\
\text { Thermal }\end{array}$ & $B$ & DK \\
\hline Anne & UK & 38 & $\begin{array}{l}\text { Married } \\
\text { with } 1 \text { child }\end{array}$ & $>£ 80,000$ & $\begin{array}{l}\text { Solar } \\
\text { Thermal }\end{array}$ & DK & $5 \mathrm{kWh}$ \\
\hline Daniel & UK & 42 & $\begin{array}{ll}\text { Married } & \\
\text { with } & 3 \\
\text { children } & \end{array}$ & $>£ 80,000$ & $\begin{array}{l}\text { Solar } \\
\text { Thermal }\end{array}$ & $B$ & 4500kW/year \\
\hline
\end{tabular}

\subsection{Reflections on the method}

As with any research, there were limitations to our approach, and given the novelty of the method, it is useful to consider how such an approach may be used in the future. In this section, we reflect on our experiences and strategies which could be employed to develop the method, principally the role of prompting, peer-to-peer discussions, and use of photographs.

Our approach to prompting was informed by our prior experience of conducting in-person research methods, learnt during training and refined in practice (cf. 77]. When formulating our journal structure and questions, we generated ideas around prompting and what we would prompt for (clarification, 
expansion, acknowledging contribution). We did not have an a priori strategy for prompting, except that we would be available online (undertaking shifts) between first thing in the morning, throughout the day, and into the evening. Prompting was thus undertaken on an ad hoc basis, aided by the sharing of fieldnotes between the two researchers. Although we were successful in generating greater contributions by prompting, on reflection, we would recommend that researchers adopting such methods develop protocols for prompting prior to use. Whilst there is some literature on moderating online discussions from a higher education perspective [79], little guidance exists for this in terms of a research project, and most literature around online moderation relates to shared or community online spaces [80]. How prompting is used in online solicited qualitative methods, beyond skype interviews [81], is not well documented. A protocol for online interaction with participants undertaking diaries may, in addition to issues such as clarification and expansion, include for example consideration of: how to respond swiftly to foster engagement (e.g. a maximum time period for response); how rapport can be developed given lack of in-person cues (e.g. shared interests, photographs); how to acknowledge the significance of their contribution is valuable (e.g. this is particularly for mundane topics where a participant may judge their knowledge as insignificant or unnoteworthy); and the way in which prompting is done (e.g. use of open ended questions 'why do you think that is'). We also found that the speed of response with participants was critical in shaping rapport which is important given the lack of in-person connection.

The theme of rapport was also important in another aspect of the method design. Although we attempted to create anonymous peer-to-peer interactive discussions for restricted elements of the journal, we found that participants were reluctant to share their experiences in this way, so almost all our data was collected via private questions (e.g. only visible between individual participants and the researchers). Our intention with the peer-to-peer discussion was to create an opportunity through which participants could collectively identify shared experiences or differences - essentially to understand the extent of consensus - and to explore why these commonalities existed (e.g. due to type of installation, or UK/NL differences). However, when we enabled peer-to-peer pages, participants would give shorter answers and no expansion. Although we did not get data on why this was the case we suggest this was perhaps due to a reluctance to share information, albeit anonymously (participants knew in advance which sections were private and which were peer-topeer, that they would not be known to each other, and we did not ask for photos in the peer-to-peer spaces). This is counter to literature that suggests online anonymity means participants are more likely to share experiences [74]. Indeed, we removed peer-to-peer sections as we progressed through the week because we felt this was counter-productive and led to less data than the private sections. 
A final reflection surrounds the use of participant photographs, which we hoped would give us greater insight into the domestic/technology contexts. In guidance at the top of each section, and in some of our prompting, we asked participants to upload photographs, resulting in collection of 75 . Participants were requested to take photographs of things that were personally significant and we assumed that this would be obvious to us. The reality was that we saw many objects that we could not interpret the significance of, including wall vents, TVs, thermostats, woodchips, and log stacks. In the future, we will provide more details to participants on what we want to see and request that for each photograph a description is included for why the image was taken, where, and when. In retrospect, a downside of the pace of the data collection period was that we failed to reflect about the photographs at the time, and this is an area where future research using online qualitative methods incorporating photographs could be developed.

Notwithstanding these reflections, that we were able to undertake synchronous collection of household journal data in two countries, across 32 households over a single week offered the possibility to do something that would otherwise have been impossible with just two researchers. The method yielded a lot of information in a short time span, including reducing the need for (international) travel, saving on transcription as contact with participants is all written and downloadable, and most importantly of all, it allows participants to make contributions as, when and where it suits them.

\section{Results}

There have been calls to 'ask how micro-generation systems become integrated, or not, into domestic routines' [11, p.139] to 'discuss the possibility of transforming people's relationships to energy in more engaging and meaningful ways' $[11$, p.140]. In response to such calls, we explore the significance of building fabric reconfiguration and the way in which the set-up of the MfH system impacted practices in the home, and over time (section 5.1). Secondly, (section 5.2) we found that living with MfH at times, but not always, led to new patterns of consumption, so we discuss the context of the participants' existing and anticipated expectations of homes. Throughout and in the following discussion section, we highlight differences in participants' accounts according to the type of technology installed and the country they lived in.

\subsection{The fabric of buildings and everyday life: issues of magnitude and legacy}

For the majority of our participants, substantial reconfiguration of the building fabric and existing layout as well as new plumbing systems, and/or improvements in energy efficiency was required at the time of an $\mathrm{MfH}$ installation. The magnitude of such change was described by our participants as minimal or inconsequential; 
'We chose to knock a bigger hole in an old fire in order to be able to use the existing chimney for the boiler (keeping it in the house). We were not bothered about making this change' (June, UK, Biomass).

'We had to make a space outside and a container to store the pellets and also get a new thermostat. These were only minimal changes so we didn't mind doing these' (Rebecca, UK, Biomass).

'We had to change the pipes as the original ones were not compatible. Luckily we have a lot of under house space and it was relatively straight forward so not stressful!' (Anne, UK, Solar Thermal).

Although our participants were overall positive about the installation process, a process they had anticipated to be disruptive and messy, for several there were unanticipated changes to the home that were required to be made post-installation. For Tanya, these changes were significant and major:

'We house the ground source heat pump in the utility room but it is rather large and in hindsight we should have built a little room for it [...] Currently we are planning to knock through the utility room wall and build a little store room for it. It is a big job though as all the pipes, etc. will need moving and it won't be cheap so we will have to budget for this over the next two years.' (Tanya, UK, Ground Source Heat Pump).

The reconfiguration of space for additional appliances to assist with some element of management of the system, such as cleaning, was also necessary for some participants: 'we have a separate vacuum cleaner, only for the stove', and as Ruben (NL, Biomass) explained he needed to make additional space to store the extra vacuum cleaner. Likewise, redecoration was another change often required and not simply at the time of installation. Indeed, one participant noted 'when you fill the woodstove up you have to open the door, so some smoke will go out... [which] gives you the opportunity for redecoration every 5 years' (Hannah, NL, Biomass).

The necessity of post-installation adaptation of the building fabric suggests that these types of changes are easier to make than, for instance, changing everyday domestic routines and practices. For example, Ruben, who built a new cupboard to store an extra vacuum cleaner could have avoided this extra work if he'd chosen to use a brush and dustpan instead. That Ruben was prepared to go through building a new cupboard and the additional cost of purchasing and using an extra vacuum, rather than adapt his everyday routine (e.g. spending more time cleaning with a brush and dustpan, or not cleaning) highlights the obduracy of domestic practices. 
Whether anticipated or not, installation or post-installation changes reflect a complex and shifting relationship between the technology, the building fabric, and everyday domestic practices. This relationship was many-directional and co-constitutive. For some of our participants, and in particular (but not always) those with biomass systems, the location of the technology within the home scripted the day-to-day experience of living with the system and the effort involved in managing or accessing it:

'our main tank is on the ground in the maintenance room. It's a nightmare to get to [to adjust/maintain] as we have had a spider outbreak in there and I'm a huge chicken!!' (Anne, UK, Solar Thermal)

'In our case, we have to remember to feed the boiler, and to be aware of how many bags of pellets are remaining (and so when to re-stock). We wanted to keep the boiler inside the house, rather than in an outbuilding, to take advantage of every single unit of heat produced! Although well insulated, there is a small amount of heat given off by the boiler and it is enough to keep the chill off the room where the boiler is - good for drying clothes' (June, UK, Biomass)

Anne and June's quotes reflect that, like most of our participants, there was a balance between the disruption of installation against the effects on everyday life. For example, 'improvements' in other facets of everyday life, such as greater opportunities for clothes drying. The legacy of the installation phase results in short term inconveniences traded or balanced against longer-term, or repetitive, habitual practices. Relatedly, participants reported how the information given during installation (e.g. about how the system worked and how it may be adjusted via thermostats or defaults) influenced everyday life:

'We're still trying to figure out the instructions' (June, UK, Biomass)

'That's really interesting - you said it was installed in March 2015 - so it is quite complex then?' (Researcher)

'We're not very technical! The system was set up by the installer and it more or less meets our requirements...but sometimes it is a bit erratic and we don't understand why. Also we'd like to vary the timing a bit but though I have tried, haven't been successful' (June, UK, Biomass)

'It is very difficult. The constructor of our home said that if we want to change anything of the installation we have to call the mechanic' (Fenna, NL, Ground Heat Pump) 'Thanks Fenna. What do you mean by 'difficult'?' (Researcher) 
'It is complex. In the menu of the system there are a lot of submenus with jargon' (Fenna, NL, Ground Heat Pump)

Assumptions made about defaults by the installer such as the timing of heating going on or off, duration of heating, or temperature, are clearly significant in shaping how the system was used, and many participants mentioned this. It raises fundamental questions about how domestic routines coincide with $\mathrm{MfH}$ systems, although specific functions such as boosters do add flexibility to MfH systems and allow householders to 'bend' the MfH system around everyday life. For example; 'We tend to pop the hot water booster on when washing up at teatime. If the kids have had a shower and a bath, we may pop the booster on again for another bath.' (Tanya, UK, Ground Source Heat Pump).

These accounts draw attention to the complexity and dialectic nature of relations between the installation and household life, for example the ways in which the physical fabric or materiality of the home shaped and was shaped by $\mathrm{MfH}$ technologies, and how the expectations around everyday domesticity (e.g. convenience, cleanliness, cosiness) may be intertwined with such changes. It also begins to suggest that the nature of changes was tied in some way to how the home and the MfH system may be used in the future.

\subsection{Existing and anticipated expectations of homes and $\mathrm{MFH}$ systems}

There was wide agreement with the sentiment that if you were thinking about an MfH installation then you should 'do your homework' (Jennifer, UK, Ground/Air Heat Pump). When asked what would have made living with $\mathrm{MfH}$ systems easier, participants expressed a huge range of different ideas, from the provision of information to 'matching' appropriate systems to homes. Many anticipated greater energy demands in the future, and had engineered installations which provided more than their current requirements:

I didn't install this personally but I know we have quite a big system for our farmhouse so it could cope with increased consumption in the future if we decided to have any extra household members. The capacity we have seems fine as we are still in early days with it and have got a system larger than our current needs' (Rebecca, UK, Biomass)

'I do believe that capacity should always be above that which is required immediately. The additional cost of providing extra capacity is minimal compared to the potential benefits of savings if upgrading is needed in the future' (Thomas, UK, Ground/Air Heat Pump) 
'I have made provision for this as we often have house guest from overseas so instead of requirement of 4 people we have done for 6 people living at home. It is better this way than other way - decreasing is simple we do not need the heating, but to increase the consumption is bit of difficult' (Jack, UK, Biomass)

'I installed a system that would be able to cope with increased consumption' (Bram, UK, Biomass)

Although these were self-reported data and we were unable to verify the actual capacity of the system in relation to the building size, that participants noted this phenomenon made it stand out as important in our analysis. Moreover, the way in which they discussed capacity was interesting. For some, it was about the size of the unit and related infrastructure itself (which was particular to biomass or GSHP, see images below) and the impact of having to install such a large object in their home. In other accounts, the capacity was discussed in terms of the heating capacity (e.g. to heat to higher temperatures, in more areas of the home, for longer periods), discussed in connection with future demand given visitors or added household members. Indeed, the likelihood of visitors or additional household members was the main explanation for increased capacity, with only one participant noting cold weather 'our system copes when we have a full house and we can tailor it to heat enough rooms to be comfortable when the weather is very, very cold' (June, UK, Biomass), and no mention of other explanations such as, for example, mistrust in contractor calculations.

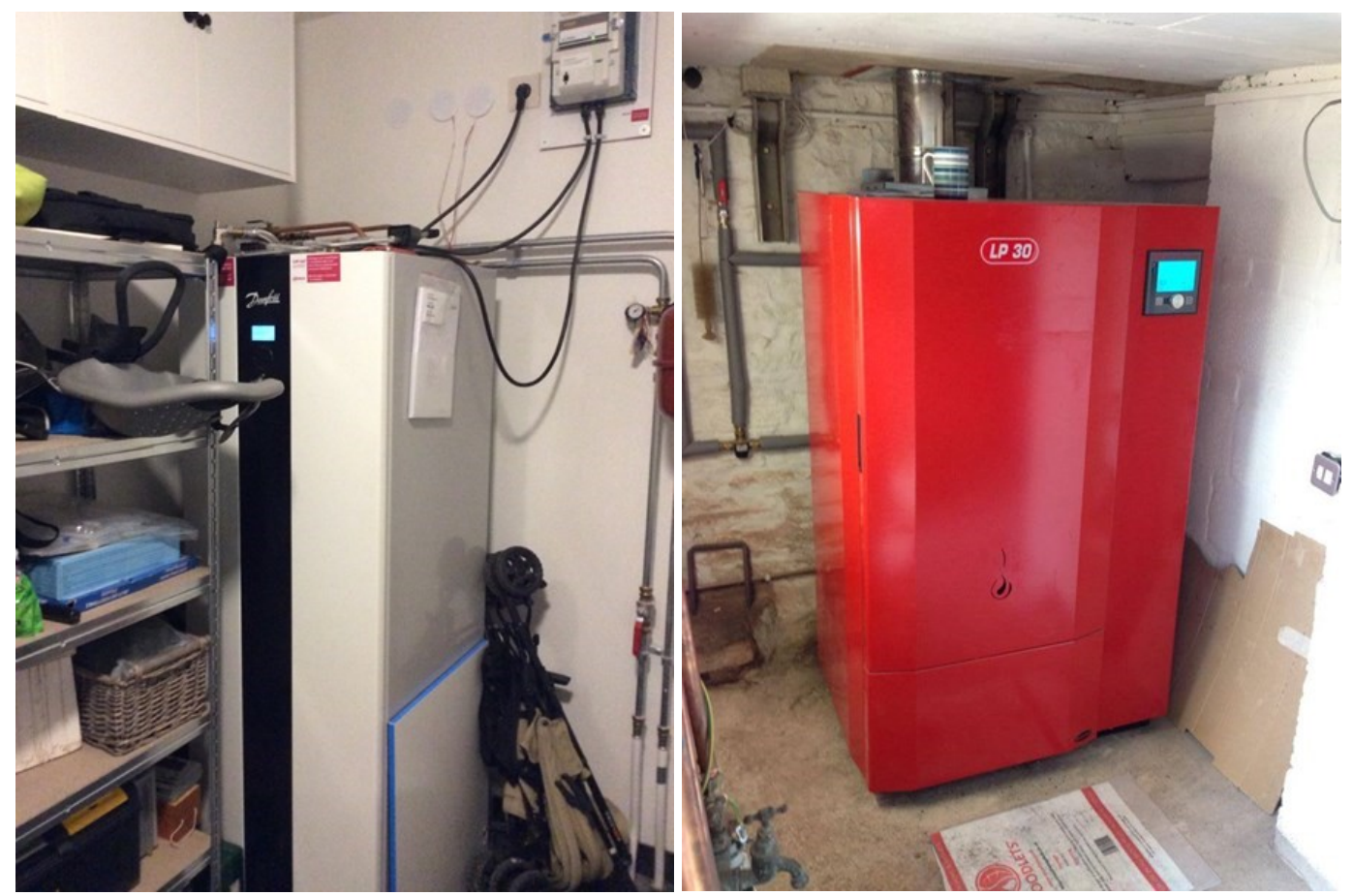

Image 1: Fenna's MfH installation (photo from participant) 
Image 2: Rebecca's MfH installation (photo from participant)

Although most participants, and particularly those with biomass systems, talked about their systems requiring hands-on engagement making them more aware and careful in their energy consumption, participants also reported their $\mathrm{MfH}$ systems resulted in greater use or demand for energy than required. Interestingly, most participants who talked about having a system which was over-capacity in this sense were based in the UK, likewise for those who talked about 'guilt-free' more-than-needed energy consumption. Whilst we do not have the data to fully explain why this may be, it is likely a consequence of cultural or regulatory/policy reasons, and is a topic worthy of future exploration, with a greater range of participating countries. Perhaps it should also encourage us to consider the specific expectations from which demand for greater capacity arises, and how demand may change in the future. Indeed, when we asked our participants what improvements they would like to make to their current homes, the changes mentioned would create significant additional energy demand as a sideeffect. For example, when talking about home improvements, 17 of our participants, almost half, reported a desire to increase the size of their home, whether that be the overall footprint, number of rooms, or size of rooms:

'It is my plan to live here for probably another two years but if I was going to be staying for longer I would like to have a two bedroomed place. This would enable me to put visitors up rather than using the settee whenever a visitor stays overnight. Therefore upgrading to a two bed place would probably be my only change' (Thomas, UK, GSHP)

'My future dream home is to have a very large house with 8-10 double bed rooms all ensuite with very large garden probably 1 acre land and that will be only for me/Spouse and our children and grandchildren and further down the line. Grow our own vegetables and fruits and the house will be most modern looking and with all modern and latest electronics products at home in Kitchen, Bathrooms, Bedrooms, Lounge, dining room with small floor for dance and well stocked Bar. It will make me feel great when I or my wife or my children invite people for Lunch or dinner. Yet I want to remain down to earth.' (Dameer, UK, Biomass).

'I would like a bigger kitchen as I love to cook and would like some more space to do so. I would also like another bedroom so I don't have to sort out sleeping arrangements if people stay over. A bigger balcony would also be good so I could entertain outside.' (Pamela, UK, GSHP) 
'I would like to build a conservatory so we can still see the sky, birds, aircrafts in the sky, also we can still sit out under the sky when it is raining. This is especially during Winter season when we hardly see sun or the birds if we are indoor in the home... we can play games there like Chess, Scrabble, Trade, Carrom and yet the bedrooms, Lounge and Dinning room (stay) neat and clean. I do have socials a lot and host parties at home, and can accommodate more friends at one time rather than have two different groups' (Jack, UK, Biomass)

Clearly, a larger home would create more demand for energy, although none of our participants acknowledged this. When asked to describe their dream home, many of our participants reiterated a desire for a larger sized home, but also included features such as swimming pools, saunas or added en-suites, which would also create additional energy demand:

'On the first floor there would be 3 bedrooms so my children and grandchild could always stay with me whenever they like. I have a bedroom with a balcony on the seaside and have a dog and a few cats. The house has a sauna on the first floor' (Julia, NL, GSHP)

I would have a small library, that would be the height of luxury. Each bedroom would be ensuite and I would have a nice dressing room. The rooms would be just a nice size, not too big so that you don't know how to fill them, but just spacious enough. I would have an indoor swimming pool and gym, plus a rasul chamber ${ }^{6}$ with a rain forest shower' (Tanya, UK, GSHP)

'My dream home would have an indoor and outdoor combined pool. It would have the latest gym' (Daniel, UK, Solar Thermal)

'My dream home would be very modern have lots of natural light have a swimming pool and an outside tranquil area with a small waterfall and exotic plants it would be based on the Moroccan Riad' (Gemma, UK, GSHP)

Indeed, we observed that participants were much more forthcoming when talking about home improvements (previous, existing and future) and dream homes than when talking about their $\mathrm{MfH}$ system - in terms of level of detail provided, the length of answers, and the justification or explanation for why they thought that way. Many of our participants simply did not know their EPC rating or their consumption, despite living in what may be regarded as high performance energy homes, but all were

\footnotetext{
${ }^{6} \mathrm{~A}$ rasul chamber is a type of steam room, traditionally found in a spa.
} 
able to articulate, and often in a detailed way, desires around improvements and their future-homes. This suggests that ideas around improvement and imagined futures are more evocative, meaningful and potentially powerful in shaping energy demand, more so than discussions around installation and use of $\mathrm{MfH}$ systems. We explore such issues in the following discussion.

\section{Discussion}

Our results support calls to look beyond simple technical or economic explanations for MfH adoption and experience $[11,27,30,38]$. Specifically, we identified that the installation of $\mathrm{MfH}$ systems impacted on the materiality of homes and practices in both anticipated and unanticipated ways. This relationship was bidirectional, with the building fabric and domestic routines influencing the location, accessibility and management of these MfH systems. Similar to Devine-Wright et al.'s [42] UK study in which the cosiness and sense of hospitality afforded by a visible heat source was identified as a barrier to the installation, satisfaction and use of $\mathrm{MfH}$, our study expands expectations of home comfort that may also undermine aims to reduce energy demand. For instance, we demonstrated how the siting, capacity and future-proofing of $\mathrm{MfH}$ systems was intertwined with anticipation of greater energy demand $[23,24,44]$. Decisions for installing overcapacity MfH were motivated by being a good host, being able to cope with extra heating or hot water demands of additional household members [38, $40,82]$. Fuller explanations of living with renewables may help inform householders' satisfaction with $\mathrm{MfH}$, and challenge approaches that are simply based on explaining adoption according to socio demographic and/or economic dimensions as outlined in section 2. For example, in our research we found that although disruption to building fabric and wider heating infrastructures (e.g. pipes, radiators) were anticipated, there were a range of other unanticipated changes (e.g. more frequent redecoration, need for greater storage space) which impacted on domestic life. These findings provide qualitative evidence to add to one of the few studies on the uptake of $\mathrm{MfH}$ [6] which suggests that 'there is a level of "hassle factor" above which uptake of heat pump technology falls away rapidly despite the existence of a robust economic incentive. This may reflect real world sensitivity' [6, p.37].

From our study, it appears that there was a legacy of impact of the installation phase, whereupon short term inconveniences were being traded-off against longer-term, or repetitive/habitual outcomes and practices. This phenomenon has also been found in the case of energy efficiency retrofitting [31], the installation of central heating systems [83] and heat pumps [26]. For example, these studies have shown how the controls of a heating system scripts the use of those systems and subsequently, everyday life. Wade et al., [83, p. 380], in their work on heating controls highlighted that installers 'perpetuate theories of home heat and how it should be organised' through, for instance, defaults (thermostat settings etc.), which influenced the timing, duration, and level of 
heating. From our analysis, we go further to suggest that it is not just theories and organisation of home heating that installers and other $\mathrm{MfH}$ professionals are shaping, but the material configuration of homes, and more broadly, expectations and aspirations relating to everyday life. For example, whether doors are left ajar to allow air to circulate [as is common for heat pumps, cf. 84] greater use of all rooms in the home, or changes in cleaning practices.

Although we were unable to verify participants' claims about their MfH systems being of greater capacity than they required to be future-proof and to cater for guests, in many accounts they did report to us that they believed their systems were larger than required. This supports the call for a more 'relational, time sensitive' understanding of energy demand [50, p.130] considering MfH is planned around visions of a future home, future life and future energy demand. STS expectations literature demonstrates how futures are not neutral and are imbued with a normative sense of what is possible, meaning that 'imaginations and trajectories for possible change should not remain exclusive and in the hands of scientific, corporate or political elites' [85, p. 204]. Understanding how householders, and not just installers, designers or regulators, anticipate the future in relation to energy-demanding domestic activities is one way to 'democratise' discussions of the future, adding valuable new perspectives to $\mathrm{MfH}$ scholarship. Moreover, moving the focus of analysis from the object, for example, $\mathrm{MfH}$ systems and their specifications, to householders' imaginings, encourages consideration of more fundamental issues such as why and how $\mathrm{MfH}$ systems are desired, and for what purpose. This enables us to understand how current energy-demanding practices co-evolve with ideals of the future, and the material impact on the type, location, and capacity (real or imagined) of the system installed. It also suggests that studies such as ours, which focus on everyday accounts of 'non-experts', may also be fruitful for those interested in STS expectations or futures scholarship as they challenge existing conceptualisations of whose futures and whose imaginations are important and why. Drawing attention to the temporality of heating practices, not just the day-to-day routines and rhythms of everyday life but the stability and future of these over time, is significant for the future of home building, retrofitting and energy planning, and a whole range of other non-energy policies [86].

\subsection{Limitations and suggestions for future work}

To conclude discussion of our findings, it is worth acknowledging our contribution to knowledge and potential limitations of our work. Firstly, and to our knowledge, ours is the first study looking across a range of different $\mathrm{MfH}$ technologies to explore experiences of these systems, as existing literature tends to focus on a specific type of technology (e.g. heat pumps, solar thermal). Thinking across technology types is productive when attempting to understand shared impacts of these technologies. 
Secondly, we attempted to undertake a cross-country exploration of domestic MfH experience. In doing so, we adopted a purposive sampling strategy, not with the intention to suggest generalisability, but to capture a range of perspectives. The reality was that the differences we discovered were more contingent on technology, for instance the difference between 'set and forget' technologies such as heat pumps, and those which required more effort such as biomass systems. However, we detected greater desirability for overcapacity of MfH systems in UK accounts. Whether this differed for cultural, regulatory/policy, or building fabric reasons, it is an interesting area for future research as crosscountry qualitative research about $\mathrm{MfH}$ or microgeneration seldom appears in the literature.

Thirdly, the online platform was a novel addition to research with householders about microgeneration technologies. With increasing numbers of people online and physical distancing measures as a result of Covid-19, it may prove to be a fruitful approach in the future, particularly if it includes an ability to link qualitative contributions to real-time online data such as that from smart meters, and other multi-media resources (e.g. video home tours, photographs). There remain, however, questions about participants' access to and confidence in using such methods.

\section{Conclusion \& implications}

In this paper we have sought to understand the experience of householders who install renewable heating systems, specifically the impact of these on their everyday life and the relationship with ideas of the future. Previous research has demonstrated the significance of positive experiences of renewable energy installations for encouraging greater uptake $[8,22,34]$, although we argue in this paper that all experiences, not just positive ones, need to be understood. This is critical when considering how relevant policies and interventions to encourage $\mathrm{MfH}$ can be delivered or adapted in the future [9].

Our key argument was that existing research overlooks the lived experience of domestic renewables, and how it is shaped by householders' imagined future practices and homes. In fact, the tension between the installation phase and the operational phase (i.e. trade-offs between structural changes and adaptations of routines/practices) could be improved through greater discussions with households. This presents a future research direction to focus on the $\mathrm{MfH}$ developer and installer to understand how they conceptualise the lived experience of these forms of heating.

Practices are hard to shift, given the importance of normative and emotional expectations of home. When seeking to develop more sustainable energy policies, current and future domestic practices are at least as important, if not more so, than building fabric. For instance, to make every day domestic life easier (i.e. not change practices), several householders were willing to make significant changes to the building fabric. The extent to which renewable heating installations encourage more sustainable 
practices remains to be seen, as in our experience, participants with renewable heating tended to report they had systems with larger capacity than required suggesting that these technologies were not necessarily demanding as little energy as they could be. This reaffirms our argument that policies around renewable heating, and efforts to reduce energy consumption through efficiency and technical means generally could work better if they recognise the social expectations and aspirations as well as the daily routines and experiences of households [48, 87, 88]. For example, as Vlasova and GramHassen $(31$, p.523) highlighted in the context of domestic retrofits, policy should focus on "how the retrofitted building can best support lower consumption related to everyday practices rather than just focusing on how to apply more efficient technology'.

We agree with Vlasova and Gram-Hassen's [31] call for more dialogic based approaches which require collective understandings of social and household expectations to identify more sustainable forms of domestic life. Our exploratory study was an attempt to investigate such understandings using an experimental online photo journal with households in two countries in a single week. In doing so, we have also generated insights about the use of this novel method with a view to informing future studies and opening a new conversation around online qualitative methods in energy and social science research.

\section{References}

1. REN21 (2016). Renewables 2016: Global Status Report, Renewable Energy Policy Network for the $21^{\text {st }}$ Century, available from http://www.ren21.net/wpcontent/uploads/2016/06/GSR 2016 Full Report REN21.pdf [accessed on 31.08.16].

2. Staffell, I., Brett, D J L., Brandon, N. (eds) (2015) Domestic Microgeneration: Renewable and Distributed Energy Technologies, Policies and Economics. New York: Routledge.

3. Kastner, I., and Matthies, E. (2016) Investments in renewable energies by German households: matter of economics, social influences and ecological concern? Energy Research \& Social Science, 17:1-9.

4. de Boer, J., Christian, Z., van Hoorn, A., and de Roo, G. (2018) The adaptation of Dutch energy policy to emerging area-based energy practices, Energy Policy, 117:142-150.

5. Connor, P.M., Xie, L., Lowes, R., Britton, J., Richardson, T. (2015) The development of renewable heating policy in the United Kingdom, Renewable Energy 75:733-744.

6. Snape, J.R., Boait, P.J., and, Rylatt, R.M. (2015) Will domestic consumers take up the renewable heat incentive? An analysis of the barriers to heat pump adoption using agentbased modelling. Energy Policy 31(85):32-38.

7. Friege, J., and Chappin, E. (2014) Modelling decisions on energy-efficient renovations; a review, Renewable Sustainable Energy Reviews, 39:196-208.

8. Michelsen, C., and Madlener, R. (2017) Homeowner satisfaction with low-carbon heating technologies, Journal of Cleaner Production, 141:1286-1292.

9. Sommerfeld, J., Buys, L., and Vine, D. (2017) Residential consumers' experiences in the adoption and use of solar PV, Energy Policy, 105:10-16.

10. Shove, E., and Walker, G. (2014) What is energy for? Social practice and energy demand. Theory, Culture \& Society, 31(5):41-58. 
11. Strengers, Y. (2013) Smart Technologies in Everyday Life: Smart Utopia? London: Palgrave Macmillan UK.

12. Delina, L., and Janetos, A. (2018) Cosmopolitan, dynamic, and contested energy futures: navigating the pluralities and polarities of the energy systems of tomorrow, Energy Research and Social Science, 35:1-10.

13. Konrad, K., Böhle, K. (2019) Socio-technical futures and the governance of innovation processes - an introduction to the special issue, Futures, 109:101-107.

14. Marques, A., Fuinhas, J., and Pereira, D. (2018) Have fossil fuels been substituted by renewables? An empirical assessment for 10 European countries, Energy Policy, 116:257265.

15. Palm, J. (2018) Household installation of solar panels - Motives and barriers in a 10-year perspective, Energy Policy, 113:1-8.

16. Ellsworth-Krebs, K., and Reid, L. (2016) 'Conceptualising energy prosumption: exploring energy production, consumption and microgeneration in Scotland, UK' Environment and Planning A, 48(10):1988-2005

17. Engelken, M., Romer, B., Drescher, M., and Welpe, I. (2018) Why homeowners strive for energy self-supply and how policy makers can influence them, Energy Policy, 117:423-433.

18. Michelsen, C., and Madlener, R. (2016) Switching from fossil fuel to renewables in residential heating systems: An empirical study of homeowners' decisions in Germany, Energy Policy, 89:95-105.

19. Franceschinis, C., Thiene, M., Scarpa, R., Rose, HJ., Moretto, M., and Cavalli, R. (2017) Adoption of renewable heating systems: an empirical test of the diffusion of innovation theory, Energy, 125:313-326.

20. Smith, A., Kern, R., Raven, R., and Verhees, B. (2013) Spaces for sustainable innovation: solar voltaic electricity in the UK. Technological Forecasting and Social Change, 81:115-130.

21. Smith, A, Vo $\beta$, J., and Grin, J. (2010) Innovation studies and sustainability transitions: the allure of the multi-level perspective and its challenges. Research Policy, 39:435-448.

22. Hercher, M., Hatzl, S., Knoeri, C., and Posch, A. (2017) The trigger matters: The decisionmaking process for heating systems in the residential building sector, Energy Policy 102:288306.

23. Hansen, A. (2018) Heating homes: Understanding the impact of prices, Energy Policy, 121:138-151.

24. Hope, A., Roberts, T., and Walker, I. (2018) Consumer engagement in low-carbon home energy in the United Kingdom: Implications for future energy system decentralisation, Energy Research \& Social Science, 44:363-370.

25. Allan, G., and McIntyre, S. (2017) Green in the heart or greens in the wallet? The spatial uptake of small renewable technologies, Energy Policy, 102:108-115.

26. Gram-Hanssen, K., Heidenstrom, N., Vitterso, G., Madsen, L., and Jacobsen, H. (2017) Selling and installing heat pumps: influencing household practices, Building Research \& Information, 45(4):359-370.

27. Heiskanen, E., and Matschoss, K. (2017) Understanding the uneven diffusion of buildingscale renewable energy systems: A review of household, local and country level factors in diverse European countries, Renewable and Sustainable Energy Reviews, 75:580-591.

28. Bickerstaff, K., Devine-Wright, P., and Butler, C. (2015) Living with low carbon technologies: an agenda for sharing and comparing qualitative energy research, Energy Policy, 84:241-249.

29. Hanna, R., Leach, M., and Torriti, J. (2018) Microgeneration: the installer perspective, Renewable Energy, 116(A):458-469.

30. Reid, L., and Ellsworth-Krebs, K. (2017) Practicing energy prosumption: Using unsolicited online data to reveal the everyday realities of solar thermal panels in the United Kingdom, Energy Research \& Social Science, 34:191-199. 
31. Vlaslova, L., and Gram-Hanssen, K. (2014) Incorporating inhabitants' everyday practices into domestic retrofits, Building Research \& Information, 42(4):512-524.

32. Bridge, G., Barr, S., Bouzarovski, S., Bradshaw, M., Brown, E., Bulkeley, H., and Walker, G. (2018) Energy and Society: A Critical Perspective. London: Routledge.

33. Sovacool, B. (2016) How long will it take? Conceptualizing the temporal dynamics of energy transitions, Energy Research \& Social Science, 13:202-215.

34. Citizens Advice (2015) A review of consumer experience of solar PV systems, available from https://www.citizensadvice.org.uk/Global/CitizensAdvice/essential\%20services\%20publicati ons/Solar\%20PV\%20Report\%20220615.pdf [Accessed 25/06/17].

35. DECC (2016) Qualitative Research with owner occupier applicants to the domestic RHI, available at:

https://assets.publishing.service.gov.uk/government/uploads/system/uploads/attachment data/file/498784/Qualitative research with owner occupier applicants to the domestic RHI.pdf [accessed 30.08.16].

36. Edling, L., and Danks, C. (2018) To adopt or not to adopt? That was our question: insights on energy transitions from a study of advanced wood heating, Energy Research and Social Science, 45:331-339.

37. Gram-Hanssen, K. (2010) Residential heat comfort practices: Understanding users, Building Research \& Information, 38(2):175-186.

38. Ellsworth-Krebs, K., Reid, L., and Hunter, C. J. (2019). Home Comfort and "Peak Household": Implications for Energy Demand. Housing, Theory and Society:1-20.

39. Hitchings, R., and Lee, S. (2008) Air conditioning and the Material Culture of Routine Human Encasement: The Case of Young People in Contemporary Singapore, Journal of Material Culture, 13(3):251-265.

40. Shove, E. (2003) Comfort, cleanliness and convenience: the social organisation of normality. Oxford: Berg.

41. Kuijer, L., and Watson, M. (2017). 'That's when we started using the living room': lessons from a local history of domestic heating in the United Kingdom, Energy Research \& Social Science, 28:77-85.

42. Devine-Wright, P., Wrapson, W., Henshaw, V., Guy, S., (2014) Low carbon heating and older adults: Comfort, cosiness and glow. Building Research and Information, 42(3):288-299.

43. Longhurst, N., and Hargreaves, T. (2019). Emotions and fuel poverty: The lived experience of social housing tenants in the United Kingdom, Energy Research \& Social Science, 56:201-207.

44. Hunter, S. (2020) Reflexive renovation and the future of household sustainability: The role of media and imagination in household consumption. Geographical Research, online first.

45. Judson, E. P., and Maller, C. (2014) Housing Renovations and Energy Efficiency: Insights from Homeowners' Practices, Building Research and Information 42(4):501-511.

46. Munro, M., and Leather, P. (2000) Nest-building or Investing in the Future? Owneroccupiers' Home Improvement Behaviour, Policy \& Politics 28(4):511-526

47. Wilson, C., Crane, L., and Chryssochoidis, G. (2015) Why Do Homeowners Renovate Energy Efficiently? Contrasting Perspectives and Implications for Policy, Energy Research and Social Science 7:12-22.

48. Roberts, E., and Henwood, K. (2019) "It's an Old House and That's How It Works": Living Sufficiently Well in Inefficient Homes, Housing, Theory and Society, 1-20.

49. Aro, R. (2017). 'A bigger living room required a bigger TV': Doing and negotiating necessity in well-to-do households, Journal of Consumer Culture, online first.

50. Ariztia, T., Fonseca, F,. and Bernasconi, O. (2019) Heating ecologies: Resituating stocking and maintenance in domestic heating, Energy Research \& Social Science, 47:128-136.

51. Anderson, B and Toritti, J. (2018) Explaining shifts in UK electricity demand using time use data from 1974 to 2014, Energy Policy, 123:544-557. 
52. Torriti, J. (2017) Understanding the timing of energy demand through time use data: Time of the day dependence of social practices, Energy Research \& Social Science, 25:37-47.

53. Granjou, C., Walker, J., Salazar, J. (2017) The politics of anticipation: on knowing and governing environmental futures, Futures, 92:5-11.

54. Groves, C. (2017) Emptying the future: on the environmental politics of anticipation,_Futures, 92:29-38.

55. Borup, M., Brown, N., Konrad, K., van Lente, H. (2006) The sociology of expectations in science and technology, Technology Analysis \& Strategic Management, 18(3-4):285-298

56. Heilscher, S., and Kivimaa, P. (2019) Governance through expectations: examining the longterm policy relevance of smart meters in the United Kingdom, Futures, 109:153-169.

57. Bornemann, B., Sohre, A., Burger, P. (2018) Future governance of individual energy consumption behaviour change - a framework for reflexive designs, Energy Research \& Social Science, 35:140-151.

58. Strengers, Y., Pink, S,. Nicholls, L. (2019) Smart energy futures and social practice imaginaries: Forecasting scenarios for pet care in Australia, Energy Research \& Social Science, 48:108-115.

59. Konrad, K., Van Lente, H., Groves, C., and Selin, C. (2017) Performing and governing the future in science and technology in C.A. Miller, U. Felt, R. Fouché, L. Smith-Doerr (Eds.), The handbook of science and technology studies (4th edition), MIT Press, Cambridge (2017), pp. 465-493.

60. Anderson, B. (2010) Preemption, precaution, preparedness: anticipatory action and future geographies, Progress in Human Geography, 34(6):777-798.

61. Tidwell, J., and Tidwell, A. (2018) Energy ideals, visions, narratives, and rhetoric: examining sociotechnical imaginaries theory and methodology in energy research, Energy Research \&Social Science 38:103-107.

62. Skjølsvold, T., and Lindkvist, C. (2015) Ambivalence, designing users and user imaginaries in the European smart grid: Insights from an interdisciplinary demonstration project, Energy Research \& Social Science, 9:43-50.

63. Sovacool, B.,, Axsen, J., and Sorrell, S. (2018) Promoting novelty, rigor, and style in energy social science: towards codes of practice for appropriate methods and research design. Energy Research \& Social Science, 45:12-42.

64. Eurostat (2016) Renewable Energy Statistics, available at: http://ec.europa.eu/eurostat/statistics-explained/index.php/Renewable energy statistics [accessed 31.08.16].

65. BEIS (2018) RHI budget caps, available at: https://assets.publishing.service.gov.uk/government/uploads/system/uploads/attachment data/file/731874/RHI budget cap publication - data to end of June 2018.pdf [accessed 31.08.16].

66. RVO (2018) ISDE Policy, available at https://translate.googleusercontent.com/translate c?depth=1\&hl=en\&prev=search\&rurl=tr anslategoogle.com\&sl=nl\&sp=nmt4\&u=https://www.rvo.nl/subsidiesregelingen/investeringssubsidieduurzame-energie-isde/isdeaanvragen/isdeparticulieren\&xid=17259,1500001,15700023,15700124,15700149,15700168, $15700186,15700191,1700201,15700208 \&$ usg=ALkJ rhhAezYSO8VoS65i4YGkYGLOBwuyOg [accessed 31.08.16].

67. Eurostat (2020) Renewable energy statistics, available at: https://ec.europa.eu/eurostat/statistics-explained/index.php/Renewable energy statistics [accessed 22.06.20].

68. Ofgem (2018) Domestic Renewable Heat Incentive (RHI) Essential guide for applicants, available at: 
https://www.ofgem.gov.uk/system/files/docs/2018/07/essentialguideforapplicants july 20 18.pdf [accessed 24.06.20].

69. Marres, N., and Gerlitz, C. (2016) Interface methods : renegotiating relations between digital social research, STS and sociology, The Sociological Review 64(1):21-46.

70. Marres, N. (2017) Digital Sociology: The Reinvention of Social Research, Polity: Cambridge.

71. Rogers, R. (2013) Digital Methods, MIT Press: Cambridge.

72. Hine, C. (2013) Virtual Research Methods (Four Volume Set), Sage Publications Limited: London.

73. Pink, S., Horst, H., Posthill, J., Hjorth, L., Lewis, T., Tacchi, J. (2015) Digital Ethnography: Principals and Practice, Sage Publications Limited: London.

74. Kozinets, R. (2010) Netnography: Doing Ethnographic Research Online, Sage Publications Limited: London.

75. Veen, M., Gremmen, B., te Molder, H. and van Woerkum, C. (2011). Emergent technologies against the background of everyday life: Discursive psychology as a technology assessment tool, Public Understanding of Science, 20(6):810-825.

76. Clark, T. (2008) 'We're Over-Researched Here!' Exploring accounts of research fatigue within Qualitative Research Engagements, Sociology, 42(5):953-970.

77. OECD (2016) European Countries by Average Wage available at: https://en.wikipedia.org/wiki/List of European countries by average wage], [accessed 31.08.16]

78. Robson, C. (2002) Real World Research, Wiley: London.

79. Baran, E., and Correia, A. (2009) Student-led facilitation strategies in online discussions, Distance Education, 30(3):339-361.

80. Lampe, C., Zube, P., Lee, J., Park, C., Johnston, E. (2014) Crowdsourcing civility: a natural experiement examining the effects of distributed moderation in online forums, Government Information Quarterly, 31(2):317-326.

81. Stewart, K., and Williams, M. (2005) Researching online populations: the use of online focus groups for social research, Qualitative Research, 5(4):395.

82. Nicholls, L., and Strengers, Y. (2019) Robotic vacuum cleaners save energy? Raising cleanliness conventions and energy demand in Australian households with smart home technologies, Energy Research \& Social Science, 50:73-81.

83. Wade, F., Shipworth, M., and Hitchings, R. (2017) How installers select and explain domestic heating controls, Building Research \& Information, 45(4):371-383.

84. Sonnberger, M., and Gross, M. (2018) Rebound effects in practice: An invitation to consider rebound from a practice theory perspective, Ecological Economics, 154:14-21.

85. Schneider, C., and Lösch, A. (2019) Visions in assemblages: Future-making and governance in fablabs, Futures, 109:203-212.

86. Royston, S., Selby, J., and Shove, E. (2018) Invisible Energy Policies: A new agenda for energy demand reduction, Energy Policy, 123:127-135.

87. Darby, S. and Fawcett, T. (2018) Energy sufficiency: an introduction. A concept paper for ECEEE. European Council for an Energy Efficient Economy.

88. Lorek, S., \& Spangenberg, J. H. (2019). Energy sufficiency through social innovation in housing, Energy Policy, 126:287-294. 